\title{
Can spleen aspirations be safely used for the parasitological diagnosis of canine visceral leishmaniosis? A study on assymptomatic and polysymptomatic animals
}

\author{
Stella Maria Barrouin-Melo ${ }^{\text {a,b,c,*, }}$, Daniela Farias Larangeira a, \\ Fernando Antônio de Andrade Filho ${ }^{c}$, Joelma Trigo ${ }^{\mathrm{d}}$, Fred Silva Julião ${ }^{\mathrm{c}}$, \\ Carlos Roberto Franke ${ }^{\mathrm{c}}$, Paulo Henrique Palis Aguiar ${ }^{\mathrm{a}, \mathrm{b}, \mathrm{c}}$, \\ Washington Luís Conrado dos-Santos ${ }^{\mathrm{a}, \mathrm{e}}$, Lain Pontes-de-Carvalho ${ }^{\mathrm{a}, \mathrm{e}}$ \\ a Centro de Pesquisas Gonçalo Moniz, Fundação Oswaldo Cruz, Rua Valdemar Falcão 121, Salvador 40295-001, Brazil

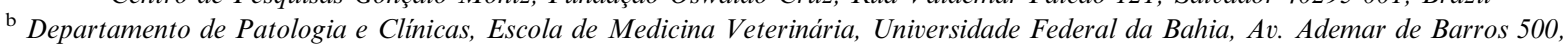 \\ Salvador 40170-000, Brazil \\ ${ }^{\mathrm{c}}$ Laboratório de Infectologia Veterinária, Escola de Medicina Veterinária, Universidade Federal da Bahia, Av. Ademar de Barros 500, \\ Salvador 40170-000, Brazil \\ d Laboratório de Doenças Tropicais, Hospital Universitário Prof. Edgar Santos, Rua João das Botas s/n, Salvador 40110-060, Brazil

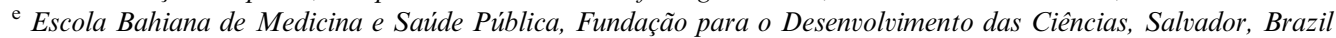

Accepted 5 November 2004

\begin{abstract}
The purpose of this study was to evaluate the safety of spleen aspiration as a sampling technique for the parasitological detection by culture and microscopy of Leishmania (chagasi) infantum. Two hundred and nine domiciled dogs from an endemic area for visceral leishmaniasis in Bahia State, Brazil, were studied.

Most dogs (87\%) were seropositive for anti-L. chagasi antibodies by ELISA. Clinical signs of disease were recorded and the animals monitored during and after spleen puncture in order to detect possible complications associated with the procedure. From a total of 257 splenic punctures in the 209 animals, only three minor events occurred, with no significant consequence for the animals and no association with risk factors. Leishmania was isolated from 149/180 (83\%) seropositive dogs, and from 6/26 (23\%) seronegative animals. The procedure did not cause adverse side effects or unnecessary suffering and confirmed the diagnosis in a large percentage of dogs. We conclude that spleen aspiration can be considered an effective and safe procedure for the definitive diagnosis of canine visceral leishmaniosis.
\end{abstract}

(C) 2004 Elsevier Ltd. All rights reserved.

Keywords: Dog; Leishmaniosis; Parasitological diagnosis; Spleen aspiration; Leishmaniasis

\footnotetext{
${ }^{*}$ Corresponding author. Tel.: +55 713564320 ext 257; fax: +55 71 3563911.

E-mail addresses: sbarrouin@cpqgm.fiocruz.br, barrouin@ufba.br (S.M. Barrouin-Melo).
}

\section{Introduction}

Dogs are considered the main reservoir of Leishmania (chagasi) infantum, the causative agent of zoonotic visceral leishmaniosis (Deane, 1961; Travi et al., 2001; Dereure et al., 2003), a disease of major public health importance in the Old and the New World (WHO, 
1990; Paranhos-Silva et al., 1998). Even in India and East Africa, where the infection is considered to be anthroponotic, dogs have been studied in an attempt to clarify the epidemiological mechanisms of dissemination of the parasite (Dereure et al., 2003).

The culling of infected animals (Borja-Cabrera et al., 2004), or their controversial treatment with antimonial drugs, are included among measures believed to control the disease (Vexenat et al., 1998). An accurate diagnostic protocol must therefore be carefully pursued by veterinarians before assigning a definitive diagnosis to a suspected or asymptomatic case.

Infected dogs can be asymptomatic, either at the beginning of the infection (Iniesta et al., 2002) or associated with an efficient Th1-type immunoinflammatory response (Pozio et al., 1981; Abranches et al., 1991; Cabral et al., 1992; Pinelli et al., 1994, 1995). In overt cases, the animals develop canine visceral leishmaniosis (CVL), a severe and progressive disease associated with a Th2biased, predominantly humoral immune response (Pinelli et al., 1994), which is incapable of containing the spread of the infection in the host organism (Ferrer et al., 1995).

The diagnosis of CVL is hindered by the range of clinical features usually associated with the disease, which is non-specific and includes a broad spectrum of presentations (Ferrer et al., 1995; Blavier et al., 2001). The usual clinical signs reported include cutaneous, periocular and ocular lesions; nephropathy and its consequences; musculoskeletal, cardiovascular, digestive, and respiratory dysfunctions; hypertrophy of the lymphoid organs and haematic disorders (Ferrer et al., 1988; Slappendel, 1988; Ciaramella et al., 1997; Peña et al., 2000; Blavier et al., 2001; Tafuri et al., 2001; Travi et al., 2001; Solano-Gallego et al., 2004). These latter signs are associated with bone marrow suppressive factors (De Luna et al., 2000), liver and kidney inflammatory injury (Ciaramella et al., 2004), hypergammaglobulinaemia and vascular damage, and are characterised by anaemia, thrombocytopenia (Pelagalli et al., 2004) and delayed coagulation time, frequently culminating with bleeding events and, in most advanced illnesses, disseminated intravascular coagulation (Blavier et al., 2001). Moreover, co-infections (BarbosaDe-Deus et al., 2002), such as ehrlichiosis, which shares many of the pathological and clinical features of CVL, are frequently observed (Llera et al., 2002).

Given these varied, non-specific clinical signs, laboratory techniques are indispensable for obtaining additional diagnostic data. Several tests have been developed in order to identify canine infection (Blavier et al., 2001; Iniesta et al., 2002), of which serological immunoassays are the most common procedures used to complement clinical data on CVL, or to identify Leishmania's antigen-seroreactive animals for epidemiological and control purposes (Iniesta et al., 2002). These tests are based on the detection of anti-Leishmania antibodies by immunofluorescence (Lanotte et al., 1975; Llera et al., 2002), ELISA (Paranhos-Silva et al., 1996; Barbosa-De-Deus et al., 2002), direct agglutination (El-Harith et al., 1989), latex agglutination (Dereure et al., 1998) or immunochromatography (Genaro et al., 1996; Reithinger et al., 2002).

Although most serological techniques are considered fast and practical, their variable sensitivity can result in underestimation of infection (Berrahal et al., 1996), and their poor specificity can lead to false-positive results, due to cross-reaction with other pathogens (Badaró et al., 1983; Barbosa-De-Deus et al., 2002; Iniesta et al., 2002). In addition, it has been demonstrated that some animals remain seronegative for long periods after being infected by Leishmania (Killick-Kendrick et al., 1994; Paranhos-Silva et al., 2003).

In places where a positive serological test is enough to justify the culling of a dog, serological failure may cause the sacrifice of unknown numbers of uninfected animals and, on the other hand, leave undetected (and consequently untreated) infected dogs (Moreno and Alvar, 2002), which could probably function as parasite reservoirs with undesirable epidemiological consequences (Dye et al., 1993; Dietze et al., 1997). More sensitive and specific techniques, such as polymerase chain reaction (PCR) (Lachaud et al., 2002), Western blotting (Berrahal et al., 1996; Aisa et al., 1998) and immunohistochemistry (Solano-Gallego et al., 2004) have been applied in research and clinical studies, but have limited routine use in diagnosis in many countries (Guerin et al., 2002). Therefore, classical parasitological methods (parasite demonstration by direct microscopy of organ aspirates and/or culture) are still used in much of the world for producing accurate results and especially to confirm a positive CVL serodiagnosis (Iniesta et al., 2002).

Recently, our research team has shown that, fineneedle spleen aspiration results in a higher frequency of parasite detection, using conventional parasitological techniques, than is obtained with lymph node aspirations (Barrouin-Melo et al., 2004). Such results would probably be improved by using the spleen aspirates for the detection of parasite DNA by PCR (Paranhos-Silva et al., 2003).

The study reported here consists of a careful evaluation of the safety of percutaneous spleen fine-needle aspiration for the diagnosis of CVL. A total of 257 spleen punctures were performed in 209 dogs, which were either asymptomatic or presenting a variety of disease signs, in an endemic area of Brazil. The animals were monitored during the procedure and, in the case of $51 \mathrm{dogs}$, for the following eight days. The sensitivity of the parasitological diagnosis, as compared with the sensitivity of serology for anti-Leishmania antibodies, and its correlation with the clinical profile and physical 
characteristics of the studied canine population are also reported.

\section{Materials and methods}

\subsection{Animals}

The 209 studied animals were from the municipalities of Lauro de Freitas, Camaçari, and Dias D’Ávila, located in the north-east of Bahia State, Brazil, an endemic area for visceral leishmaniosis. Other canine diseases, such as ehrlichiosis, babesiosis and dirofilariasis, share endemicity with CVL in that area. All of the animals were referred to local veterinarians for one or more of the following reasons: they had signs of disease, had been tested seropositive for leishmaniosis by the Municipal Zoonosis Control Services, or lived in the same house as an infected or seropositive animal.

The group of animals was heterogeneous, including mongrel and purebred dogs, of both sexes, with different body sizes and ages varying from six months to 12 years of age. All animals were domiciled and belonged to owners with different socioeconomic conditions.

The procedures we carried out were in accordance with guidelines defined by the Committee of Ethics in Animal Experimentation of the Oswaldo Cruz Foundation, Bahia, Brazil.

\subsection{Serodiagnosis}

The presence of anti-Leishmania antibodies in the sera of all 209 studied dogs was investigated by a classical indirect ELISA, using soluble $L$. chagasi antigens (SLA), as described by Paranhos-Silva and collaborators (1996). The presence of anti-K39 antibodies was assessed, in the sera of the 51 dogs maintained in a veterinary hospital for a short-term follow up, by an indirect ELISA using the K39 recombinant Leishmania antigen, as described previously (Badaró et al., 1996). The SLA consisted of the soluble fraction (the supernatant of a $10,000 \mathrm{~g}, 30 \mathrm{~min}$ centrifugation) of lysed promastigotes from a local Leishmania strain, isolated from a sick dog, and characterised as $L$. chagasi by means of isoenzyme electrophoresis plus comparison with a reference strain (LTCC - Leishmania Typing Culture Collection - WDCM731).

All determinations were carried out in triplicate and the mean values above the cut-off were considered to be positive results. The cut-off value was determined by the receiver operating characteristics (ROC) curve, using corrected absorbance values obtained with sera from 30 L. chagasi-infected dogs, positive in serological and parasitological tests, and from 71 healthy dogs, living in LCV non-endemic areas (Griner et al., 1981). One dog was serologically tested for ehrlichiosis by a com- mercial ELISA test kit (SNAP 3Dx, IDEXX Laboratories).

\subsection{Clinical evaluation}

All dogs were clinically examined for the presence and severity of signs associated with visceral leishmaniasis, such as lesions in the skin and mucous membranes, changes in colour of the mucous membranes, abnormal growth of the claws, ocular and conjunctival disorders, presence of abnormal discharges, weight loss, changes in mental attitude and general disposition, changes in size of lymph nodes and spleen, bleeding events, as well as history and clinical signs of infections other than leishmaniosis, before being subjected to the splenic aspirations.

\subsection{Splenic aspiration}

The animals were tranquilized with an intravenous injection of $0.5 \mathrm{mg} / \mathrm{kg}$ acepromazine and restrained in right lateral recumbency. The hair was removed and asepsis was done on the skin over the site of puncture, with a $2 \%$ iodine-alcohol solution. Needles of two gauges were used, $18 \mathrm{G} \times 38 \mathrm{~mm}$ or $21 \mathrm{G} \times 32 \mathrm{~mm}$, for dogs above or below $10 \mathrm{~kg}$ body weight, respectively, connected to a $10 \mathrm{~mL}$ sterile syringe.

The spleen was localised by palpation. During the procedure, the needle was introduced at a ventrally tilted plane, forming a $45^{\circ}$ angle with the normal, and a $45^{\circ}$ angle with the cranio-caudal line, in the left flank, 1$3 \mathrm{~cm}$ (depending on the animal size) from the ventral extremity of the last rib, on a projection of this rib towards the abdominal midline (Fig. 1). After perforating the spleen by introducing about $1-3 \mathrm{~cm}$ of needle, according to the dog size, in the animal abdomen, the gentlest negative pressure that allowed the passage of a blood-like, thick material into the syringe was made by pulling manually the syringe's piston. The whole aspiration procedure usually took a few seconds, and yielded samples of approximately $100-200 \mu \mathrm{L}$. The material was kept inside the syringes, on ice, until being seeded into culture medium, in the laboratory.

Sixteen animals were subjected to more than one spleen puncture, with intervals that varied from one to three months: six animals were subjected to two punctures because the first aspirate was contaminated by fungus; one animal was subjected to three punctures and nine animals to five punctures in a study aimed at investigating the effect of short-term chemotherapy on spleen parasitism (unpublished data).

\subsection{Follow-up of animals after spleen aspiration}

The main complications that could happen during or after spleen puncture were: (a) intracavity abdominal 


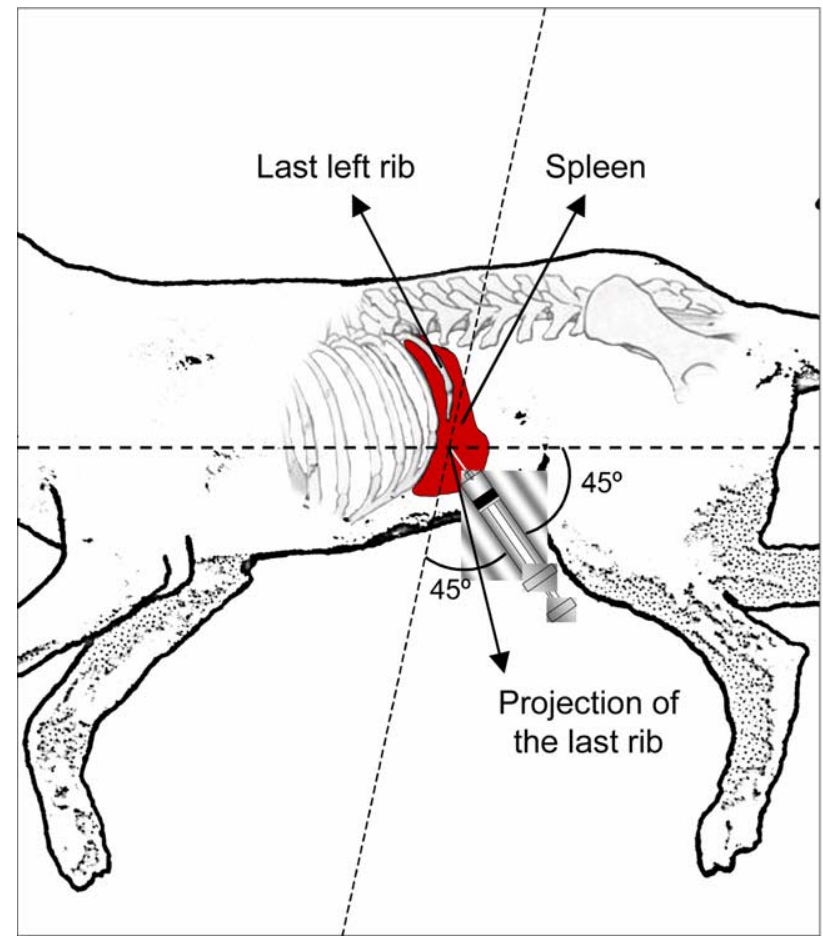

Fig. 1. Angle of introduction, direction and position of the needle for spleen aspiration in most dogs. The position on the projection of the last rib may vary from 1 to $3 \mathrm{~cm}$ of the rib extremity, depending on the animal's size.

haemorrhage due to laceration of the spleen, or formation of large haematomas; or (b) skin, subcutaneous, peritoneal, visceral or systemic infection, including abscess formation.

The animals were monitored by clinical evaluation, with assessment of physiological parameters (cardiac, pulse and respiratory frequencies, body temperature, colour and moistness of mucous membranes and capillary refill time), behaviour and facial expression. Particular attention was given to possible evidence of acute blood loss (e.g., tachycardia, lethargy, weak femoral pulses, pale mucous membranes, slow capillary refill time, abdominal distension) or of chronic bleeding/ haematoma formation, especially progressive changes in overall demeanour and jaundice.

Investigation of potential signs of infection focused on the presence of fever, abdominal pain or distension and physiological malfunctions. Aggressive or submissive postures, loss of greeting behaviour, withdrawal from or lack of interest in the surrounding environment, depression, stupor, agitation, restlessness, anorexia, insomnia, changes in grooming or elimination habits, altered facial expression and vocalisation were considered as pain signs. Additional clinical evidence of blood loss or infections included tachypnoea, mydriasis, salivation, oedema, sensitivity to palpation or manipulation, areas of hyperalgesia or allodynia and alteration of body posture.
The animals were kept under observation immediately after spleen puncture and until complete recovery from sedation, which usually lasted from 30 to $60 \mathrm{~min}$. Fifty-one dogs, subjected to splenic aspirations in a veterinary hospital, were kept in individual cages in the hospital's premises for eight days after spleen puncture, and were examined daily in accordance with the parameters listed above. The remaining 158 dogs were subjected to splenic aspiration under field conditions in their homes. In the case of these dogs, a new clinical evaluation was carried out on the eighth day after the procedure, and information on possible complications in this eight-day period was obtained by daily phone contact with the owner. Reports or findings of any abnormality would entail an immediate thorough clinical re-examination of the animal, including laboratory tests, such as blood counts, serum biochemistry, or other diagnostic procedures, such as abdominocentesis, radiographic and ultrasonographic evaluation.

\subsection{Examination and culture of splenic aspirates}

The spleen aspirates were cultured in a biphasic medium containing $1.5 \mathrm{~mL}$ of blood-agar solid medium and $2 \mathrm{~mL}$ of Schneider's medium (Sigma Chemical Co.) supplemented with $20 \%$ of fetal bovine serum (Gibco, BRL). Cultures were maintained at $23{ }^{\circ} \mathrm{C}$ and examined weekly under light microscopy for one month. The presence of live, active promastigote forms was considered to be a positive result. The direct microscopic examination of spleen aspirates was not performed in most animals in order to minimise the manipulation of aspirates, which could possibly result in fungal or bacterial contamination of the cultures. When the aspirates macroscopically differed from the usual, blood-like aspect of a splenic aspirate, however, they were examined under optical microscopy to investigate their nature.

\subsection{Statistical analysis}

The significance of the differences observed between groups was tested by Fisher's exact probability test for cross tables using proportions (Glantz, 2001). In all tests the accepted level of significance corresponded to $P<0.05$.

\section{Results}

\subsection{Clinical profile of the animals}

Clinical signs of disease were present in 177/209 $(84.7 \%)$ dogs (Table 1). They included cutaneous changes (alopecia, depigmentation, exfoliation, nodules ulceration and/or pustule formation); onychogryphosis; mucous membrane colour changes (paleness, 
Table 1

Clinical and physical characteristics of a canine population suspected of having visceral leishmaniosis in an endemic area of Bahia, Brazil, and the presence of Leishmania in splenic aspirates

\begin{tabular}{|c|c|c|c|}
\hline \multirow[t]{2}{*}{ Characteristics } & \multirow{2}{*}{$\begin{array}{l}\text { Number of dogs with } \\
\text { characteristics/total } \\
\text { number of dogs with } \\
\text { recorded data }(\%)\end{array}$} & \multicolumn{2}{|l|}{ Spleen parasitism } \\
\hline & & Positive cultures (\%) & Negative cultures $(\%)$ \\
\hline \multicolumn{4}{|l|}{ Gender } \\
\hline Male & $94 / 155^{\mathrm{A}}(61)$ & $66(70)$ & $28(30)$ \\
\hline Female & $61 / 155(39)$ & $43(70)$ & $18(30)$ \\
\hline \multicolumn{4}{|l|}{ Age } \\
\hline$\leqslant 1$ years & $10 / 155(6)$ & $9(90)$ & $1(10)$ \\
\hline$>1$ to $\leqslant 6$ years & $119 / 155(77)$ & $84(71)$ & $35(29)$ \\
\hline$>6$ years & $26 / 155(17)$ & $16(62)$ & $10(38)$ \\
\hline \multicolumn{4}{|l|}{ Body size } \\
\hline Small & 16/155 (10) & $10(63)$ & $6(37)$ \\
\hline Medium & 38/155 (24) & $26(68)$ & $12(32)$ \\
\hline Large & $104 / 155(66)$ & $73(72)$ & $28(28)$ \\
\hline \multicolumn{4}{|l|}{ Clinical findings } \\
\hline Any clinical sign & $175 / 206(85)$ & $140(80)^{\mathrm{a}}$ & $35(20)^{\mathrm{a}}$ \\
\hline No clinical sign & $31 / 206(15)$ & $15(49)$ & $16(51)$ \\
\hline Previous bleeding & $7 / 155(4)$ & $7(100)$ & $0(0)$ \\
\hline Skin lesions & $120 / 155(77)$ & $90(75)^{b}$ & $30(25)^{\mathrm{b}}$ \\
\hline Mucous membrane lesions & $39 / 155(25)$ & $36(92)^{\mathrm{c}}$ & $3(8)^{\mathrm{c}}$ \\
\hline Ocular changes & $28 / 155(19)$ & $24(86)^{\mathrm{d}}$ & $4(14)^{\mathrm{d}}$ \\
\hline Splenomegaly & $150 / 206(73)$ & $121(81)^{\mathrm{e}}$ & $29(19)^{\mathrm{e}}$ \\
\hline Normal lymph nodes & $28 / 109(26)$ & $16(57)$ & $12(43)$ \\
\hline Reduced lymph nodes & $3 / 109(3)$ & $3(100)$ & $0(0)$ \\
\hline Enlarged lymph nodes & 78/109 (72) & $60(77)$ & $18(23)$ \\
\hline Cachexia & $6 / 155(4)$ & $6(100)^{\mathrm{f}}$ & $0(0)^{f}$ \\
\hline Emaciation & $74 / 155(47)$ & $58(78)^{f}$ & $16(22)^{\mathrm{f}}$ \\
\hline Normal weight & $73 / 155$ (48) & $44(60)^{f}$ & $29(40)^{\mathrm{f}}$ \\
\hline Overweight & $2 / 155(1)$ & $1(50)^{\mathrm{f}}$ & $1(50)^{\mathrm{f}}$ \\
\hline Prostration & $6 / 206(3)$ & $6(100)^{\mathrm{g}}$ & $0(0)^{\mathrm{g}}$ \\
\hline Apathy & $38 / 206$ (19) & $30(79)^{\mathrm{g}}$ & $8(21)^{\mathrm{g}}$ \\
\hline Normal activity & $162 / 206(79)$ & $119(74)^{\mathrm{g}}$ & $43(26)^{\mathrm{g}}$ \\
\hline \multicolumn{4}{|l|}{ Serology } \\
\hline Positive & 180/206 (87) & $149(83)^{\mathrm{h}}$ & $31(17)^{\mathrm{h}}$ \\
\hline Negative & $26 / 206(13)$ & $6(23)^{\mathrm{h}}$ & $20(77)^{\mathrm{h}}$ \\
\hline
\end{tabular}

A Numbers $\leqslant 155$ refer to animals studied under field conditions (in their homes); 206 refers to the whole group of studied animals, minus three animals that had contaminated spleen cultures.

${ }^{a}$ Fisher exact probability test: $P=0.0004$.

b $P=0.0174$

c $P=0.0002$.

${ }^{\mathrm{d}} P=0.0361$.

e $P=0.0005$.

${ }^{f}$ Cachexia + emaciation vs. regular weight + overweight, $P=0.0052$.

${ }^{g}$ Prostration + apathy vs. normal activity, $P=0.036$

h $P<0.0001$.

icterus or congestion); mucous membrane nodular or ulcerative lesions, particularly on the lips and nose; ocular disturbances (conjunctivitis, keratitis, keratoconjunctivitis sicca, blepharitis and/or uveitis); weight loss; apathy or prostration; splenomegaly; lymphadenopathy; epistaxis and gingival or abnormal genital bleeding. Furthermore, 35/158 dogs $(22.1 \%)$ had a history of previous clinical diagnosis and treatment for ehrlichiosis or babesiosis.

\subsection{Complication rate during or after fine-needle puncture}

After sedation, no animal displayed any evidence of pain or suffering, apart from a few animals that made slight body movements during the needle introduction into the skin. Among the 257 spleen punctures performed in the 209 animals, only three $(1.2 \%)$ resulted in undesirable events. In two dogs, the macroscopic characteristics of the aspirates were suggestive of intestinal 
material. This was confirmed by microscopic examination, which disclosed the presence of numerous bacteria. These two dogs were kept in hospital for close monitoring, and, since there was never any sign of peritonitis or local infection, no antibiotic or anti-inflammatory therapy was instituted.

None of the 209 studied animals developed any signs of peritonitis or local infection. Another animal, kept under field conditions, developed a $10 \mathrm{~cm}$ diameter haematoma in the skin around the point of needle introduction immediately after the procedure, probably due to a vessel injury. This particular animal had Ehrlichia infection, as assessed by a serological test. There was no progression of the haemorrhage in this animal. Neither the bowel perforations nor the haematoma formation appeared to be related to size of spleen or previous spontaneous bleeding.

Apart from the haematoma, no other incidents or complications were observed by physical examination performed (1) during the first 30-60 min following spleen aspiration in all dogs, (2) daily during the first eight days after the spleen aspiration in 51 dogs, and (3) on the eighth day after the procedure in all dogs. The physiological parameters of all 209 dogs were within the ranges of normality, as measured during the physical examinations mentioned above.

\subsection{Evidence of infection with Leishmania and its relationship with clinical findings}

Indirect ELISA showed that $87.1 \%(182 / 209)$ of the dogs were seropositive, having a specific humoral response against $L$. chagasi soluble (LCS) or K39 recombinant antigens. The cultures of spleen aspirates from the 209 dogs yielded 155 positive $(74.2 \%)$, 51 negative $(24.4 \%)$ and $3(1.4 \%)$ inconclusive results, the latter due to fungal contamination. The distribution of animals in which Leishmania was identified in groups of dogs displaying different physical, clinical and serological characteristics, is shown in Table 1 . The three animals with inconclusive culture results were excluded from this correlation analysis.

The frequency of splenic parasitism was not influenced by the gender or the body size of the animals. There was no significant difference in the occurrence and distribution of parasitism and the average age of the groups analysed. However, emaciation and cachexia, depression and apathy, cutaneous, mucous membrane and ocular changes, as well as splenomegaly, and positive serology, were significantly more frequent in animals with positive spleen culture. The presence of at least one clinical sign was observed in 90.3\% (140/155) of the dogs in the parasite-positive group, and in $68.6 \%(35 / 51)$ of dogs in the negative-parasite group $(P=0.0004)$.
Positive results in anti-Leishmania antibody serological tests were not statistically associated with age, body size, gender, and depression/apathy, but were associated with the presence of signs of disease $(P=0.000081)$, including splenomegaly $(P=0.0008)$, skin lesions $(P=0.0069)$, mucous membrane lesions $(P=0.0006)$ and ophthalmic disorders $(P=0.049)$. There was no statistically significant association between spleen parasitism or positive serology and changes in lymph nodes.

The culture carried out with splenic aspirates identified parasites in 149/180 (83\%) seropositive dogs, and in $6 / 26(23 \%)$ seronegative animals.

\section{Discussion}

This study, together with others carried out by our group (Paranhos-Silva et al., 2003; Barrouin-Melo et al., 2004), show that fine-needle splenic puncture is an effective procedure for the parasitological diagnosis of CVL, yielding adequate samples for the in vitro cultivation of parasites. In addition to its efficacy, the technique has been shown to be safe both in hospital premises and in the home as well as in dogs with very different clinical profiles. The procedure was performed in 57 dogs with normal spleen sizes and 152 animals with different degrees of splenomegaly, as determined by palpation, with identical success.

The 209 studied dogs, from a Brazilian area where leishmaniosis is highly endemic, had clinical conditions that varied from asymptomatic, seronegative animals in contact with infected animals (12 dogs), to seriously ill animals (six dogs), displaying a picture of terminal CVL. Moreover, 35 animals had a history or evidence of concurrent infectious diseases, namely ehrlichiosis and babesiosis, and could possibly have had other infections as the studied area also harbours a number of other pathogens such as Dirofilaria immitis, Leptospira spp. (Paraguassu and Fielder, 1997; Viegas et al., 2001) and intestinal worms.

In fact, the dogs we studied closely reflected the infected population in an endemic area for CVL. Their clinical profile (Table 1) agrees with those seen in other endemic areas (Blavier et al., 2001; França-Silva et al., 2003; Borja-Cabrera et al., 2004). The majority of infected dogs was seropositive, and had more clinical signs, namely cutaneous, mucosal, ocular and periocular lesions, as well as splenomegaly, than parasitologically negative animals. The absence of correlation with some characteristics, such as gender and age, agrees with the reports of Pozio et al. (1981), Abranches et al. (1991) and França-Silva et al. (2003), but disagrees with others (Lanotte et al., 1975; Cardoso et al., 2004), indicating the need for further epidemiological studies.

Fine-needle biopsy of the spleen has been used in the diagnosis of leishmaniosis in human beings (Guerin 
et al., 2002) and dogs (Strauss-Ayali et al., 2004), as well as in other canine (Stockhaus et al., 1998; Christopher, 2003), feline (O'Keefe and Couto, 1987; Hickford et al., 2000) and human diseases (Kraus et al., 2001; Fritscher-Ravens et al., 2003; Zeppa et al., 2003). Reports focusing on the safety of the procedure, however, are few and concern human patients, utilising, in most cases, ultrasonographic guidance (Bonifacio et al., 2000; Civardi et al., 2001; Lal et al., 2003).

In two previous studies, our team has reported the use of fine-needle spleen aspirations in the diagnosis and follow-up of dogs, either clinically healthy or with patent visceral leishmaniosis, kept under laboratory or in field conditions (Paranhos-Silva et al., 2003; Barrouin-Melo et al., 2004). Some of these animals were subjected to multiple spleen punctures during the course of 13 months without adverse effects related to the procedure (Paranhos-Silva et al., 2003). These studies, however, involved a small number of animals, and safety aspects of the procedure were not their major concern.

Because some animals were punctured more than once, a total of 257 splenic punctures were carried out in the present study in order to obtain a definitive parasitological diagnosis of the infection. Among these 257 procedures, only three adverse incidents occurred: bowel puncture in two animals, and the formation of a skin haematoma at the site of puncture in another. This dog with haematoma lived in an area where ehrlichiosis is prevalent, had fever, depression, enlarged spleen and lymph nodes, and was heavily infested with skin parasites, including ticks, which are known to be Ehrlichia vectors. Ehrlichiosis was indeed confirmed by serological test. The animal was therefore infected by both Leishmania, which was detected in its spleen aspirate, and Ehrlichia and its clinical condition improved after antibiotic therapy for ehrlichiosis. The haematoma formation, which was self-contained, could have been aggravated either by the putative Ehrlichia infection and/or by CVL, as both conditions have been associated with bleeding disorders (Slappendel, 1988; Ciaramella et al., 2004).

In the group of dogs we studied, 35 either had overt clinical signs of bleeding disorders or history of ehrlichiosis. Evidence of bleeding abnormalities or anaemia should be one of the major contra-indications for splenic puncture, due to the possibility of internal haemorrhage, as happens with human patients (Guerin et al., 2002; Lal et al., 2003). Fortunately, no evidence of internal haemorrhage was found in the present study. A particularly remarkable finding, however, was the absence of puncture-associated complications even in the animals showing spontaneous bleeding (e.g., epistaxis).

The two dogs that had their bowel accidentally aspirated did not show any complications following the occurrence, during the eight-day follow-up. The other 49 hospital-punctured animals were also closely fol- lowed for eight days with no abnormality detected. A major concern was peritonitis, abdominal infections and/or septicaemia. Although examination for the presence of bacteria in 207/209 aspirates was not performed, no evidence of local or systemic infections was observed in any of the dogs. Moreover, there was no evidence of any other complication in the 158 dogs that were subjected to splenic puncture under field conditions.

In many countries parasitological methods still offer the most reliable results for the routine confirmation of $L$. chagasi infection in veterinary medicine. It is also probable that the use of spleen aspirates as samples for PCR, would improve the sensitivity of this molecular technique, making the procedure useful in countries where PCR is readily available. Our findings confirm the safety of the technique (a 100\% success rate was observed in the 257 aspirations) with no clinically relevant complications. We conclude that splenic aspiration can be indicated as a safe procedure for obtaining live parasites for in vitro cultures for the diagnosis of CVL or to obtain splenic tissue for other tests including PCR assays. However, it should be stressed that a thorough knowledge of canine anatomy and experience in veterinary practice is fundamental for carrying out the technique, which should only be done by a veterinary surgeon.

\section{Acknowledgements}

This work was supported by the Brazilian National Council for Research and Technological Development (CNPq). We thank Ms. Fabiola Nascimento da Conceição for reviewing the English language.

\section{References}

Abranches, P., Santos-Gomes, G., Rachamin, N., Campino, L., Schnur, L.F., Jaffe, C.L., 1991. An experimental model for canine visceral leishmaniasis. Parasite Immunology 13, 537-550.

Aisa, M.J., Castillejo, S., Gállego, R., Fisa, R., Riera, M.C., Colmenares, M., Torras, S., Roura, X., Sentís, J., Portús, M., 1998. Diagnostic potential of Western blot analysis of sera from dogs with leishmaniasis in endemic areas and significance of the pattern. American Journal of Tropical Medicine and Hygiene 58, $154-159$.

Badaró, R., Reed, S.G., Carvalho, E.M., 1983. Immunofluorescent antibody test in American visceral leishmaniasis: sensitivity and specificity of different morphological forms of two Leishmania species. American Journal of Tropical Medicine and Hygiene 32, 480-484.

Badaró, R., Benson, D., Eulálio, M.C., Freire, M., Cunha, S., Netto, D., Pedral-Sampaio, D., Madureira, C., Burns, J.M., Houghton, J.R., David, J.R., Reed, S.G., 1996. RK39: a cloned antigen of Leishmania chagasi that predicts active visceral leishmaniasis. Journal of Infectious Diseases 173, 758-761.

Barbosa-De-Deus, R., Dos Mares-Guia, M.L., Nunes, A.Z., Costa, R.G., Junqueira, R.G., Mayrink, W., Genaro, O., Tavares, C.A., 
2002. Leishmania major-like antigen for specific and sensitive serodiagnosis of human and canine visceral leishmaniasis. Clinical and Diagnostic Laboratory Immunology 9, 1361-1366.

Barrouin-Melo, S.M., Larangeira, D.F., Trigo, J., Aguiar, P.H.P., Dos-Santos, W.L.C., Pontes-de-Carvalho, L., 2004. Comparison between splenic and lymph node aspirations as sampling methods for the parasitological detection of Leishmania chagasi infection in dogs. Memórias do Instituto Oswaldo Cruz 99, 195-197.

Berrahal, F., Mary, C., Roze, M., Berenger, A., Escoffier, K., Lamouroux, D., Dunan, S., 1996. Canine leishmaniasis: identification of asymptomatic carriers by polymerase chain reaction and immunoblotting. American Journal of Tropical Medicine and Hygiene 55, 273-277.

Blavier, A., Keroack, S., Denerolle, P., Goy-Thollot, I., Chabanne, L., Cadore, J.L., Bourdoiseau, G., 2001. Atypical forms of canine leishmaniosis. The Veterinary Journal 162, 108-120.

Bonifacio, A., Goldberg, R.E., Patterson, B.J., Haider, M., 2000. Flow-cytometry enhanced fine-needle aspiration biopsy of the spleen. Canadian Association of Radiologists Journal 51, 158-162.

Borja-Cabrera, G.P., Cruz-Mendes, A., Paraguai-de-Souza, E., Hashimoto-Okada, L.Y., Trivellato, F.A., Kawasaki, J.K., Costa, A.C., Reis, A.B., Genaro, O., Batista, L.M., Palatnik, M., Palatnik-de-Sousa, C.B., 2004. Effective immunotherapy against canine visceral leishmaniasis with the FML-vaccine. Vaccine 22, 2234-2243.

Cabral, M., O'Grady, J., Alexander, D., 1992. Demonstration of Leishmania specific cell mediated and humoral immunity in asymptomatic dogs. Parasite Immunology 14, 531-539.

Cardoso, L., Rodrigues, M., Santos, H., Schoone, G.J., Carreta, P., Varejão, E., van Benthem, B., Afonso, M.O., Alves-Pires, C., Semiao-Santos, S.J., Rodrigues, J., Schallig, H.D., 2004. Seroepidemiological study of canine Leishmania spp. infection in the municipality of Alijo (Alto Douro, Portugal). Veterinary Parasitology 121, 21-32.

Christopher, M.M., 2003. Cytology of the spleen. Veterinary Clinics of North America Small Animal Practice 33, 135-152.

Ciaramella, P., Oliva, G., Luna, R.D., Gradoni, L., Ambrosio, R., Cortese, L., Scalone, A., Persechino, A., 1997. A retrospective clinical study of canine leishmaniasis in 150 dogs naturally infected by Leishmania infantum. Veterinary Record 141, 539-543.

Ciaramella, P., Pelagalli, A., Cortese, L., Pero, M.E., Corona, M., Lombardi, P., Avallone, L., Persechino, A., 2004. Altered platelet aggregation and coagulation disorders related to clinical findings in 30 dogs naturally infected by Leishmania infantum. The Veterinary Journal, doi:10.1016/j.tvj1.2004.03.009.

Civardi, G., Vallisa, D., Berte, R., Giorgio, A., Filice, C., Caremani, E., Caturelli, E., Pompili, M., De-Sio, I., Buscarini, E., Cavanna, L., 2001. Ultrasound-guided fine needle biopsy of the spleen: high clinical efficacy and low risk in a multicenter Italian study. American Journal of Hematology 67, 93-99.

Deane, L.M., 1961. Reservoirs of Leishmania donovani in Brazil. Revista da Associação Médica Brazileira 7, 161-169.

De Luna, R., Ferrante, M., Severino, L., Ambrosio, R., Piantedosi, L., Gradoni, L., Lucisano, A., Persechino, A., 2000. Decreased lipid fluidity of the erythrocyte membrane in dogs with leishmaniasis-associated anaemia. Journal of Compared Pathology 122, 213-216.

Dereure, J., Lanotte, G., Pratlong, F., Gouvernet, J., Majhour, J., Belazzoug, S., Khiami, A., Rageh, H.A., Jarry, D., Perieres, J., Rioux, J.A., 1998. Canine leishmaniasis from Leishmania infantum: value and production of the latex test. Ecoepidemiologic applications. Bulletin de la Société de Pathologie Exotique 91, 300-305.

Dereure, J., El-Safi, S.H., Bucheton, B., Boni, M., Kheir, M.M., Davoust, B., Pratlong, F., Feugier, E., Lambert, M., Dessein, A., Dedet, J.P., 2003. Visceral leishmaniasis in eastern Sudan: parasite identification in humans and dogs; host-parasite relationships. Microbes and Infection 5, 1103-1108.
Dietze, R., Barros, G.B., Teixeira, L., Harris, J., Michelson, K., Falqueto, A., Corey, R., 1997. Effect of eliminating seropositive canines on the transmission of visceral leishmaniasis in Brazil. Clinical and Infectious Diseases 25, 1240-1242.

Dye, C., Vidor, E., Dereure, J., 1993. Serological diagnosis of leishmaniasis: on detecting as well as disease. Epidemiology and Infection 103, 647-656.

El-Harith, A., Slappendel, R.J., Reiter, I., van-Knapen, F., de-Korte, E., Huigen, E., Kolk, A.H., 1989. Application of a direct agglutination test for detection of specific anti-Leishmania antibodies in the canine reservoir. Journal of Clinical Microbiology 27, 2252-2257.

Ferrer, L., Rabanal, R., Fondevilla, D., Ramos, J.A., Domingo, M., 1988. Skin lesions in canine leishmaniosis. Journal of Small Animal Practice 29, 381-388.

Ferrer, L., Aisa, M.J., Roura, X., Portús, M., 1995. Serological diagnosis and treatment of canine leishmaniasis. Veterinary Records 136, 514-516.

França-Silva, J.C., da-Costa, R.T., Siqueira, A.M., Machado-Coelho, C.A., da-Costa, C.A., Mayrink, W., Vieira, E.P., Costa, J.S., Genaro, O., Nascimento, E., 2003. Epidemiology of canine visceral leishmaniosis in the endemic area of Montes Claros Municipality, Minas Gerais State, Brazil. Veterinary Parasitology 111, 161-173.

Fritscher-Ravens, A., Mylonaki, M., Pantes, A., Topalidis, T., Thonke, F., Swain, P., 2003. Endoscopic ultrasound-guided biopsy for the diagnosis of focal lesions of the spleen. American Journal of Gastroenterology 98, 1022-1027.

Genaro, O., Melo, M.A., Costa, R.T., França-Silva, J.C., Arias, J.R., Monteiro, P., Reed, S.G., Badaró, R., 1996. Evaluation of the immunochromatography assay for the diagnosis of canine visceral leishmaniasis. A prospective study on experimentally infected dogs with Leishmania chagasi. Memórias do Instituto Oswaldo Cruz 91, 63-70.

Glantz, S.A., 2001. Primer of Biostatistics, fifth ed. McGraw Hill Inc., New York, 545p.

Griner, P.F., Mayewski, R.J., Mushlin, A.I., Greenland, P., 1981. Selection and interpretation of diagnostic tests and procedures. Annals of Internal Medicine 94, 555-600.

Guerin, P.J., Olliaro, P., Sundar, S., Boelaert, M., Croft, S.L., Desjeux, M.K., Wasunna, M.K., Bryceson, A.D., 2002. Visceral leishmaniasis: current status of control, diagnosis, and treatment, and a proposed research and development agenda. The Lancet Infectious Diseases 2, 494-501.

Hickford, F.H., Stokol, T., Vangessel, Y.A., Randolph, J.F., Schermerhorn, T., 2000. Monoclonal immunoglobulin G cryoglobulinemia and multiple myeloma in a domestic shorthair cat. Journal of the American Veterinary Medical Association 217, 1029-1033, 1007-1008.

Iniesta, L., Fernández-Barreto, S., Bulle, B., Gómez, M.T., Piarroux, M., Gállego, M., Alunda, J.M., Portús, M., 2002. Diagnostic techniques to detect cryptic leishmaniasis in dogs. Clinical and Diagnostic Laboratory Immunology 9, 1137-1141.

Killick-Kendrick, R., Killick-Kendrick, M., Pinelli, E., del-Real, G., Molina, R., Vitutia, R., Canavante, M.M., Nieto, J., 1994. A laboratory model of canine leishmaniasis: the inoculation of dogs with Leishmania infantum promastigotes from midguts of experimentally infected phlebotomine sandflies. Parasite 1, 311-318.

Kraus, M.D., Fleming, M.D., Vonderheide, R.H., 2001. The spleen as a diagnostic specimen: a review of 10 years' experience at two tertiary care institutions. Cancer 91, 2001-2009.

Lachaud, L., Chabbert, E., Dubessay, P., Dereure, J., Lamothe, J., Dedet, J.P., Bastien, P., 2002. Value of two PCR methods for the diagnosis of canine visceral leishmaniasis and the detection of asymptomatic carriers. Parasitology 125, 197-207.

Lal, A., Ariga, R., Gattuso, P., Nemcek, A.A., Nayar, R., 2003. Splenic fine needle aspiration and core biopsy. A review of 49 cases. Acta Cytologica 47, 951-959. 
Lanotte, G., Rioux, J.A., Croset, H., Vollhardt, Y., 1975. Écologie des leishmaniosis dans le sud de la France. VIII. Complément à l'application epidémiologique de la technique d'immunofluorescence: les titres geometrices et arithmetiques dans la leishmaniose canine. Annales de Parasitologie Humaine et Comparée 50, 1-5.

Llera, J.L.G., Garcia, M.L.L., Reinoso, E.M., González, R.V., 2002. Differential serological testing by simultaneous indirect immunofluorescent antibody test in canine leishmaniosis and ehrlichiosis. Veterinary Parasitology 109, 185-190.

Moreno, J., Alvar, J., 2002. Canine leishmaniasis: epidemiological risk and the experimental model. Trends in Parasitology 18, 399-405.

O'Keefe, D.A., Couto, C.G., 1987. Fine-needle aspiration of the spleen as an aid in the diagnosis of splenomegaly. Journal of Veterinary Internal Medicine 1, 102-109.

Paraguassu, A.A, Fielder, H., 1997. Ocorrência de Dirofilaria immitis em cães na cidade de Salvador, Bahia, Brazil. Arquivos da Escola de Medicina Veterinária UFBA 2, 99-105.

Paranhos-Silva, M., Freitas, L.A.R., Dos-Santos, W.L.C., Grimaldi, L., Pontes-de-Carvalho, L., Oliveira-dos-Santos, A.J., 1996. A cross-sectional serodiagnostic survey of canine leishmaniasis due to Leishmania chagasi. American Journal of Tropical Medicine and Hygiene 51, 39-44.

Paranhos-Silva, M., Nascimento, E.G., Melro, M.C., Oliveira, W.L.C., Dos-Santos, W.L.C., Pontes-de-Carvalho, L., Oliveirados-Santos, A.J., 1998. Cohort study on canine emigration and Leishmania infection in an endemic area for American visceral leishmaniasis: implications for the disease control. Acta Tropica 69, 75-83.

Paranhos-Silva, M., Oliveira, G.G.S., Reis, E.A., Menezes, R.M.C., Fernandes, O., Sherlock, I., Gomes, R.B.B., Pontes-de-Carvalho, W.L.C., Dos-Santos, W.L.C., 2003. A follow-up of Beagle dogs intradermally infected with Leishmania chagasi in the presence or absence of sand fly saliva. Veterinary Parasitology 114, 97-111.

Pelagalli, A., Ciaramella, P., Lombardi, P., Pero, M.E., Cortese, L., Corona, M., Oliva, G., Avallone, L., 2004. Evaluation of adenosine $5^{\prime}$-diphosphate (ADP)- and collagen-induced platelet aggregation in canine leishmaniasis. Journal of Comparative Pathology 130, 124-129.

Peña, M.T., Roura, X., Davidson, M.G., 2000. Ocular and periocular manifestations of leishmaniasis in dogs: 105 cases (1993-1998). Veterinary Ophthalmology 3, 35-41.

Pinelli, E., Killick-Kendrick, R., Wagenaar, J., Bernadina, W., Del Real, G., Ruitenberg, J., 1994. Cellular and humoral immune responses in dogs experimentally and naturally infected with Leishmania infantum. Infection and Immunity 62, 229-235.

Pinelli, E., Gonzalo, R.M., Boog, C.J., Rutten, V.P., Gebhard, D., Del Real, G., Ruitenberg, E.J., 1995. Leishmania infantum-specific T cell lines derived from asymptomatic dogs that lyse infected macrophages in a major histocompatibility complex-restricted manner. European Journal of Immunology 25, 1594-1600.

Pozio, E., Gradoni, L., Bettini, S., Gramiccia, M., 1981. Leishmaniasis in Tuscany (Italy): IV. Canine leishmaniasis in the focus of Monte Argentario (Grosseto). Acta Tropica 38, 383-393.

Reithinger, R., Quinnell, R., Alexander, B., Davies, C.R., 2002. Rapid detection of Leishmania infantum in dogs: comparative study using an immunochromatographic dipstick test, enzyme-linked immunosorbent assay, and PCR. Journal of Clinical Microbiology 40, 2352-2356.

Slappendel, R.J., 1988. Canine leishmaniasis. A review based on 95 cases in The Netherlands. The Veterinary Quarterly 10, 1-16.

Solano-Gallego, L., Fernandez-Bellon, H., Morell, P., Fondevila, D., Alberola, J., Ramis, A., Ferrer, L., 2004. Histological and immunohistochemical study of clinically normal skin of Leishmania infantum-infected dogs. Journal of Comparative Pathology 130, 7 12.

Stockhaus, C., Slappendel, R.J., Haemophagocytic, C., 1998. Syndrome with disseminated intravascular coagulation in a dog. Journal of Small Animal Practice 39, 203-206.

Strauss-Ayali, D., Jaffe, C.L., Burshtain, O., Gonen, L., Baneth, G., 2004. Polymerase chain reaction using noninvasively obtained samples, for the detection of Leishmania infantum DNA in dogs. Journal of Infectious Diseases 189, 1729-1733.

Tafuri, W.L., de-Oliveira, M.R., Melo, M.N., Tafuri, W.L., 2001. Canine visceral leishmaniosis: a remarkable histopathological picture of one case reported from Brazil. Veterinary Parasitology 96, 203-212.

Travi, B.L., Tabares, C.J., Cadena, H., Feroo, C., Osorio, Y., 2001. Canine visceral leishmaniasis in Colombia: relationship between clinical and parasitologic status and infectivity for sand flies. American Journal of Tropical Medicine and Hygiene 64, 119-124.

Vexenat, J.A., Olliaro, P.L., Fonseca-de-Castro, J.A., Cavalcante, R., Furtado-Campos, J.H., Tavares, J.P., Miles, M.A., 1998. Clinical recovery and limited cure in canine visceral leishmaniasis treated with aminosidine (paromomycin). American Journal of Tropical Medicine and Hygiene 58, 448-453.

Viegas, S.A., Caldas, E.M., Oliveira, E.E., 2001. Aglutininas antiLeptospira em hemosoro de animais domésticos de diferentes espécies no Estado da Bahia, Brazil, 1997-1999. Revista Brazileira de Saúde e Produção Animal 1, 1-6.

WHO, 1990. Control of the leishmaniasis: report of a WHO Expert Committee. World Health Organization, Geneva. Technical Report Series 793.

Zeppa, P., Picardi, M., Marino, G., Troncone, G., Fulciniti, F., Vetrani, A., Rotoli, B., Palombini, L., 2003. Fine-needle aspiration biopsy and flow cytometry immunophenotyping of lymphoid and myeloproliferative disorders of the spleen. Cancer 99, 118-127. 